\title{
Effects of dietary assessment methods on assessing risk of nutrient intake adequacy at the population level: from theory to practice
}

\author{
Lourdes Ribas-Barba ${ }^{1}$, Lluís Serra-Majem ${ }^{1,2}$, Blanca Román-Viñas ${ }^{1}$, Joy Ngo $^{1}$ and Alicia García-Álvarez ${ }^{1}$ \\ ${ }^{1}$ Community Nutrition Research Centre of the Nutrition Research Foundation, University of Barcelona Science Park, Baldiri \\ Reixac 4, Torre D, 4A1, 08028 Barcelona, Spain \\ ${ }^{2}$ Department of Clinical Sciencies, University of Las Palmas de Gran Canaria, PO Box 550, 35080 Las Palmas \\ de Gran Canaria, Spain
}

(Received 5 March 2009 - Revised 6 May 2009 - Accepted 1 June 2009)

\begin{abstract}
The present study evaluated how applying different dietary methods affects risk assessment of inadequate intakes at the population level. A pooled analysis was conducted using data from two Spanish regional representative surveys both applying similar methodology with a total sample of 2615 individuals aged 12-80. Diet was assessed in the entire sample applying data from one $24 \mathrm{~h}$ recall (24HR), a mean of two non-consecutive 24HR, both crude and adjusted for intraindividual variability, and a FFQ. Intakes of vitamins A, C, E, thiamin, riboflavin, niacin, vitamin $\mathrm{B}_{6}$, vitamin $\mathrm{B}_{12}, \mathrm{Fe}, \mathrm{Mg}, \mathrm{P}$ and $\mathrm{Zn}$ were compared to the average nutrient requirement (ANR or estimated average requirement) in the entire sample and also excluding under-reporters applying the ANR cut-point method (and the probability approach for Fe). Higher percentages of intakes below the ANR were seen for $1-24 \mathrm{HR}$ and the mean of $2-24 \mathrm{HR}$, except for nutrients with the highest rates of inadequacy (vitamins $\mathrm{A}, \mathrm{E}$, folate and $\mathrm{Mg}$ ). For these micronutrients, higher percentages of inadequacy were obtained by adjusted 24HR data and the lowest with FFQ. For the remaining nutrients, adjusted data gave the lowest inadequacy percentages. The best concordance was seen between $2-24 \mathrm{HR}$ and $1-24 \mathrm{HR}$ as well as for adjusted 24HR, with the least observed between FFQ and the other methods. Exclusion of under-reporters considerably reduced inadequacy in both daily methods and FFQ. Crude daily data gave higher estimates of inadequate intakes than adjusted data or FFQ. Reproducibility of daily methods was also reasonably good. Results may differ depending on the micronutrient thus impeding reaching conclusions/recommendations common for all micronutrients.
\end{abstract}

Dietary methods: Nutrition assessment: Nutrient adequacy: Dietary surveys: $24 \mathrm{~h}$ Recall

Does a gold standard exist for dietary survey methods that assess nutrient intake of an individual or of a group? Ideally, nutritional epidemiology would like to have access to a rapid dietary interview that is economic, easy to administer and applicable to a range of populations, irrespective of age, educational level or ethnicity. It should also facilitate access to this information in a non-invasive manner, yielding a valid and thorough assessment of the nutritional status of the target population that allows for subsequent identification of nutrition problems and the elaboration and/or evaluation of nutrition policies and interventions, such as the elaboration of food guides, with the objective of improving the population's health status ${ }^{(1,2)}$.

The majority of existing dietary surveys allows for the estimation of what individuals or populations consume, but none of them can unequivocally estimate the true level of nutritional inadequacy. There are a plethora of factors that affect the exactness of data obtained from nutrition surveys, such as the selected dietary survey instrument (if intake measured is usual or actual, the number of days evaluated, etc.), whether it is interviewer or self-administered, the type of interviewee (direct or by proxy), data entry (if data collected were directly entered on location using specific computer software or if information was collected on paper and subsequently codified and entered), and the voluntary/ involuntary error in reporting foods consumed with under/ over-reporting of intake both in quantity and in types of food (omission of foods consumed or reporting foods that were not consumed $)^{(1-4)}$. Moreover, error is also introduced in the estimation of portion sizes, derived from distinct visual supports such as household measures, photographs, bi/tri-dimensional models, standard measures, etc. In addition, when the objective is to measure not only food but rather nutrient intake, there are even more factors that can affect

Abbreviations: ANR, average nutrient requirement; EFCOSUM, European food consumption survey method; INL 98 , individual nutrient level at $98 \%$; $24 \mathrm{HR}, 24 \mathrm{~h}$ recall.

On behalf of EURRECA's RA 1.1 'Intake Methods' members: Serra-Majem L (Coordinator), Cavelaars A, Dhonukshe-Rutten R, Doreste JL, Frost-Andersen L, García-Álvarez A, Glibetic M, Gurinovic M, De Groot L, Henríquez-Sánchez P, Naska A, Ngo J, Novakovic R, Ortiz-Andrellucchi A, Øverby NC, Pijls L, Ranic M, Ribas-Barba L, Ristic-Medic D, Román-Viñas B, Ruprich J, Saavedra-Santana P, Sánchez-Villegas A, Tabacchi G, Tepsic J, Trichopoulou A, van 't Veer P, Vucic V,Wijnhoven TMA.

* Corresponding author: Lluís Serra-Majem, fax +34 9340345 43, email fin@pcb.ub.cat 
their correct estimation: food composition tables utilised (if they are complete and updated in terms of foods and nutrient values, if information is available for prepared foods, brand names or fortified foods, etc.), the inclusion of information about vitamin and mineral supplements consumed, the bioavailability of the nutrient under study, etc. ${ }^{(1,2,5,6)}$.

A critical aspect of dietary intake assessment is the variability of the diet. This is affected on one hand by inter-subject or between-variability (subjects differ from each other in their true intake) and by intra-subject or within-variability on the other hand, which consists of variability in food or nutrient intake within the same individual from one day to another. In many cases and for certain nutrients, intra-subject variability is usually greater than inter-subject variability ${ }^{(2,7,8)}$. Inter-subject variability of intake is especially influenced by factors such as age and sex, whereas intra-subject variability is subject to other aspects including, among others, the day of the week, season of the year or health status. For example, meals consumed on weekends are generally different than what is consumed during the week - with Sunday meals being more copious, which also occurs at special celebrations. Intake over non-consecutive days is more diverse than consumption over consecutive days in which food may be prepared and eaten for $2 \mathrm{~d}$ in a row, or leftovers may be eaten the following day. During working days, meals are frequently consumed outside the home such as the school/ office/etc. ${ }^{(2,8,9)}$. The season of the year is also an influencing factor $^{(2,8-10)}$. Despite the fact of globalisation and that markets of developed countries have a greater variety of food available all year long, a certain degree of seasonality still exists for given foods such as fruits, vegetables and beverages. As for health status, mild health disorders such as having the flu, diarrhoeal episodes, etc. can also impact on food selection. Chronic health problems may also lead to monotonous dietary patterns. This day to day variability in intake is less frequently observed in developing countries in which the typical diet is more monotonous. In addition, age is also a factor where less variety has been observed in the dietary intake of small children ${ }^{(11)}$. Other aspects such as having completed previous dietary interviews may also lead to changes in eating habits. Different statistical methods that allow for adjusting intake data to obtain usual intake have been developed so as to minimise the effect of intraindividual variability $^{(2,12-14)}$.

The selection of the diet instrument to be used in nutrition surveys requires that certain decisions be made, which will have a decisive effect on the degree of accuracy of the results obtained. Many factors impact on this decision, the primary being the objective of the study, the study design, demographic characteristics of the population (age, socio-economic level, literacy, disease prevalence, level of motivation, etc.) and available resources (economic, material and human) ${ }^{(1)}$. As such, the diet assessment method selected will not always be what a priori is considered the most adequate for achieving the objective of the study. On the other hand, although nutrition surveys are designed to meet set objectives, survey-derived data are frequently utilised for other purposes. For these reasons, it is good to be aware of how study results may be affected by the distinct survey methods administered and how these results should be interpreted and applied.
The present analysis forms part of the work on intake methods focusing on nutrient intake adequacy assessment that was carried out as part of the European Union EURopean micronutrient RECommendations Aligned (EURRECA) Network of Excellence ${ }^{(15)}$. It aims to evaluate how applying different dietary instruments affects risk assessment of inadequate intakes at the population level. Nutrient adequacy using information from different dietary assessment methods one $24 \mathrm{~h}$ recall $(24 \mathrm{HR})$, a mean of two non-consecutive 24HR with both raw and adjusted data for intra-individual variability and a FFQ - derived from intake data in the same individuals was analysed. The approach used to evaluate nutrient adequacy in the present article was the average nutrient requirement (ANR) cut-off point (ANR or estimated average requirement) ${ }^{(16)}$ and in the case of $\mathrm{Fe}$ the probability approach was applied. The analysis evaluated the effect of excluding under-reporters. The present study did not aim to evaluate the prevalence of nutrient inadequacy in a specific country but rather to compare the data obtained from different dietary survey instruments applied to the same individuals. Within this context, data from Spanish regional nutrition surveys that had the same methodology and dietary information were analysed.

\section{Methods}

The present study analysed data derived from a pooled analysis of two regional cross-sectional random population surveys, the Catalan Nutrition Survey 2002-3 $3^{(17,18)}$ and the Canary Island Nutrition Survey $1997-8^{(19,20)}$. Both surveys used the same methodology, which is summarised as follows.

\section{Curs Catalan Nutrition Survey-2002-3}

The Catalan Nutrition Survey Study on nutritional status and food habits of the Catalan population, a crosssectional population survey, was carried out between 2002 and 2003 on a random sample of the Catalan population aged 10-85 years, ( $n$ 2160; 954 men and 1106 women), selected by multistage random sampling procedures based on a population census. This survey was carried out as part of the nutritional status monitoring system of the Catalan population, periodically undertaken by the Department of Health of the Catalan government every 10 years. Catalonia is a region of Europe located in north eastern Spain bordered to the north by France and to the east by the Mediterranean Sea. It has a population of more than seven million inhabitants, having its own language called Catalan as well as its particular history and culture. In 1979, when the Autonomous Community Statute was approved, Catalonia acquired its own government and the ability to organise itself within the framework of the Spanish State.

In this survey, a $24 \mathrm{HR}$ was conducted to evaluate food consumption and nutrient and energy intakes and $62 \%$ of the sample answered a second 24HR 8-30d later, administered on a day that differed from the first interview. Household measures found in the subjects' own homes were used to estimate volumes and portion sizes. Interviews were conducted on all days of the week throughout the entire year. In coding the $24 \mathrm{HR}, 635$ codes were utilised. The Centre 
d'Ensenyament Superior de Nutrició i Dietètica Spanish food composition table ${ }^{(21)}$ was chosen to convert food to energy and nutrients and results were adjusted for intraindividual variability $^{(12,13)}$. A quantitative 80 -item FFQ was used to evaluate food habits. Household measures found in the subjects' own homes were also used to quantify amounts of food consumed. The composition of each FFQ item was obtained by weighting the composition of the main foods in that line item based on the intake data from the $24 \mathrm{HR}$. A general questionnaire compiled information about socioeconomic variables (profession, level of education, etc.) as well as food habits, chronic disease control, smoking, physical activity, attitudes, opinion and knowledge about nutrition, nutrition education and food safety. The questionnaire ended with questions on anthropometry, and measurements were taken in standard conditions (weight, height, waist and hip circumference, etc.). The survey interviews, always conducted in the subject's home, were carried out by a total of twenty-two dieticians, who had previously undergone an intensive training programme. Fieldwork took place from March 2002 to June $2003^{(17,18)}$.

\section{Canary Islands Nutrition Survey-1997-8}

The Canary Islands Nutrition Survey status and food habits of the population from the Canary Islands, a cross-sectional population survey, was carried out between 1997 and 1998 on a random sample of the population aged 6-75 years, ( $n$ 1747; 821 men and 926 women), selected by multistage random-sampling procedures based on a population census $^{(19,20)}$. This study was carried out as part of the nutritional status monitoring system of the population from the Canary Islands. The Canary Islands show some remarkable peculiarities from a geographical and sociocultural point of view. They are located $1600 \mathrm{~km}$ away from southwest Spain in the Atlantic Ocean, in close proximity to the African coast $(100 \mathrm{~km}$ from south western Morocco). Geographically, the islands are part of the African continent, yet from a historical, economic, political and sociocultural point of view, the Canary Islands are completely European. The Archipelago consists of seven main islands as well as a number of smaller ones. The Canary Islands presently have a population of about 2 million inhabitants ( 1.5 million at the time, the field work of the study was carried out).

In order to evaluate food consumption and nutrient and energy intakes, two $24 \mathrm{HR}$ were conducted in non-consecutive days within a period of $15 \mathrm{~d}$. The second recall was conducted on a different day to that of the first interview. Household measures found in the subjects' own homes were used to estimate volumes and portion sizes. Interviews were conducted on all days of the week throughout the entire year. Four hundred and thirty codes were used to code the 24HR. The Spanish food composition table from Mataix et al. ${ }^{(22)}$ was chosen to convert food into energy and nutrients, and results were adjusted for intraindividual variability following the procedures described by Liu et al. ${ }^{(12)}$ and Beaton et al. ${ }^{(13)}$. A semiquantitative 80 -item FFQ was used to evaluate food habits. The composition of each FFQ item was obtained by weighting the composition of the main foods in that line item based on the intake data obtained through the 24HR. A general questionnaire compiled information about socio-economic variables (profession, level of education, etc.) as well as food habits, chronic disease control, smoking, physical activity, attitudes, opinion and knowledge about nutrition, nutrition education and food safety. The questionnaire ended with questions on anthropometry, and measurements were taken in standard conditions for the following parameters: weight, height, waist, hip and arm circumference, elbow breadth and hypertension. The biochemical analysis was carried out on a subsample. The survey interviews, always taking place at the subject's home, were carried out by seventeen dieticians, who had previously undergone an intensive training programme. Field work took place from February 1997 to January 1998.

\section{Statistical analysis}

Variables of both surveys were homogenised and the two databases merged. For the purpose of this analysis, only subjects 12 years and older with available data on energy and nutrient intakes derived from the four methods (i.e. one $24 \mathrm{HR}$, a mean of two non-consecutive $24 \mathrm{HR}$ with both raw and adjusted data for intra-individual variability and a FFQ) were included. The Goldberg cut-off method was used to detect under-reporters, defined as the cases in which the ratio between energy intake and the $\mathrm{BMR}$ - calculated from the equations proposed by the FAO/WHO/UNU dependent on male and female body weight $(\mathrm{kg})-$ was $<1 \cdot 14^{(23)}$. The Institute of Medicine ${ }^{(24)}$ and the $\mathrm{WHO}^{(25)}$ nutrient reference values were used for the calculation of inadequate intakes. The present article presents the analysis of inadequate intake risk defined as a population with intakes below the ANR cut-off point, and in the case of Fe the probability approach was used, given that the distribution of the requirement for $\mathrm{Fe}$ does not follow a symmetrical distribution, and as such the ANR cut-point method is not applicable ${ }^{(26-27)}$.

\section{Analysis}

The data were analysed using the SPSS statistical package version 15.0 (SPSS, Inc., Chicago, IL, USA). Prevalence of vitamin and mineral intakes (vitamins $\mathrm{A}, \mathrm{C}$ and $\mathrm{E}$, thiamin, riboflavin, niacin, vitamin $\mathrm{B}_{6}$, folate, vitamin $\mathrm{B}_{12}, \mathrm{Mg}, \mathrm{P}$ and $\mathrm{Zn}$ ) below the ANR and inadequate Fe intake estimated by the probability approach were calculated according to each of the four methods, for the entire sample and by sex. The same analysis was carried out on under-reporters. Concordance analysis between the different methods for given nutrients (vitamin $\mathrm{C}$, folate, vitamin $\mathrm{B}_{12}$ and $\mathrm{Zn}$ ) involved the calculation of the sensitivity and specificity and the $\kappa$ test (agreement categories: no agreement (negative values), poor agreement $(0-0 \cdot 2)$, slight agreement $(0 \cdot 2-0 \cdot 4)$, fair agreement $(0 \cdot 4-0 \cdot 6)$ and good agreement $(>0 \cdot 6))$. $\mathrm{Zn}$ data were derived exclusively from the Catalan Nutrition Survey, since the food composition database used in the Canary Islands Nutrition Survey did not include values for $\mathrm{Zn}$.

\section{Results}

The final database included a total of 2615 subjects aged 12-80 years (1258 men and 1357 women), out of which 
Table 1. Percentage of population with intakes below ANR cut point by $\operatorname{sex}^{*}$

\begin{tabular}{|c|c|c|c|c|}
\hline & One $24 \mathrm{HR}$ & Two 24HR & $24 \mathrm{HR}$ adjusted & FFQ \\
\hline \multicolumn{5}{|l|}{ Men ( $n$ 1258) } \\
\hline Vitamin A & 55.6 & $54 \cdot 2$ & $70 \cdot 0$ & 21.4 \\
\hline Vitamin C & $42 \cdot 6$ & $36 \cdot 6$ & 29.9 & $13 \cdot 0$ \\
\hline Vitamin E & 74.6 & 75.9 & 94.6 & $46 \cdot 2$ \\
\hline Thiamin & 31.4 & $26 \cdot 1$ & 11.4 & $19 \cdot 7$ \\
\hline Riboflavin & $18 \cdot 1$ & $14 \cdot 9$ & $4 \cdot 8$ & 8.4 \\
\hline Niacin & $12 \cdot 4$ & $7 \cdot 3$ & 0.4 & 3.8 \\
\hline Vitamin $\mathrm{B}_{6}$ & $16 \cdot 0$ & $12 \cdot 0$ & $2 \cdot 8$ & $6 \cdot 4$ \\
\hline Folate & $80 \cdot 4$ & 83.9 & 97.5 & $66 \cdot 0$ \\
\hline Vitamin $B_{12}$ & $10 \cdot 1$ & 4.4 & 0.0 & 0.7 \\
\hline Fe† & $5 \cdot 7$ & $2 \cdot 7$ & 0.1 & 1.5 \\
\hline $\mathrm{Mg}$ & $63 \cdot 2$ & $66 \cdot 8$ & $80 \cdot 7$ & $50 \cdot 0$ \\
\hline $\mathrm{P}$ & 3.7 & $2 \cdot 3$ & 0.4 & 0.9 \\
\hline $\mathrm{Zn}$ & $50 \cdot 7$ & $48 \cdot 7$ & $61 \cdot 3$ & $42 \cdot 9$ \\
\hline \multicolumn{5}{|c|}{ Women ( $n$ 1357) } \\
\hline Vitamin A & 48.9 & $42 \cdot 1$ & $46 \cdot 4$ & $10 \cdot 3$ \\
\hline Vitamin C & 35.9 & 29.7 & $16 \cdot 4$ & $6 \cdot 1$ \\
\hline Vitamin E & $82 \cdot 7$ & $85 \cdot 0$ & $98 \cdot 7$ & $55 \cdot 0$ \\
\hline Thiamin & 39.1 & 35.0 & 20.9 & $18 \cdot 7$ \\
\hline Riboflavin & $14 \cdot 0$ & $10 \cdot 3$ & 1.0 & 3.4 \\
\hline Niacin & $18 \cdot 8$ & $12 \cdot 0$ & 0.4 & 4.4 \\
\hline Vitamin $\mathrm{B}_{6}$ & 24.5 & $21 \cdot 0$ & $5 \cdot 2$ & 6.9 \\
\hline Folate & $85 \cdot 3$ & 88.6 & 99.4 & $66 \cdot 4$ \\
\hline Vitamin $B_{12}$ & $17 \cdot 5$ & $8 \cdot 8$ & 0.3 & $1 \cdot 1$ \\
\hline Fe† & $52 \cdot 4$ & $51 \cdot 7$ & 55.9 & 37.4 \\
\hline $\mathrm{Mg}$ & $55 \cdot 8$ & $55 \cdot 6$ & $62 \cdot 1$ & $26 \cdot 5$ \\
\hline $\mathrm{P}$ & 7.4 & $5 \cdot 3$ & 0.9 & 1.8 \\
\hline $\mathrm{Zn}$ & $35 \cdot 8$ & 34.9 & $23 \cdot 4$ & $20 \cdot 0$ \\
\hline
\end{tabular}

ANR, average nutrient requirement (or estimated average requirement); $24 \mathrm{HR}$, $24 \mathrm{~h}$ recall.

*Pooled analysis of Spanish data. Population aged 12-80 years.

$\dagger$ Fe: calculated by the probability approach.

seventy-three did not have weight data and were not included in the under-reporter analysis ( $n$ 2542; 1223 men and 1319 women).

Table 1 presents the percentage of the entire sample that had intakes of the considered nutrients below the ANR, by sex, and according to each of the four dietary methods of analysis used. Table 2 presents inadequate intake percentages for the entire sample and excluding under-reporters. Fig. 1 illustrates the results of Table 2 for one $24 \mathrm{HR}$, data adjusted for intra-individual variability and the FFQ.

Comparison by sex (Table 1) shows significant differences in the percentages of intakes below the ANR for all nutrients considered in the four methods used except for niacin, vitamin $\mathrm{B}_{12}$ and $\mathrm{P}$ when comparing adjusted data, and thiamin, niacin, vitamin $\mathrm{B}_{6}$, folate and vitamin $\mathrm{B}_{12}$ when comparing FFQ data by sex. Inadequate intake percentages obtained by the four methods are greater in males when compared with females for vitamin $\mathrm{A}$, vitamin $\mathrm{C}$, riboflavin, $\mathrm{Mg}$ and $\mathrm{Zn}$, and for the rest of nutrients inadequacy percentages are greater in females.

Inadequate intake percentages differed considerably depending on the nutrient chosen and on the dietary instrument used. For most nutrients, greater values were observed when only a single $24 \mathrm{HR}$ was used, followed by when the mean of the two $24 \mathrm{HR}$ was applied; smaller values were observed when data adjusted for intra-individual variability were used, except for nutrients with the highest percentage of the population with intakes below the ANR (vitamins A and $\mathrm{E}$, folate and $\mathrm{Mg}$ ). For these four nutrients, inadequacy percentages were the highest when adjusted data were used and minimum percentages were observed when the FFQ was used (Tables 1 and 2).

The percentage of under-reporters changed depending on the instrument used, with values $>40 \%$ when using daily methods and $28 \%$ when using the FFQ. The percentage of subjects classified as under-reporters in the four modes of analysis was $18.6 \%$ (230 men (18.6\%) and 243 women $(18.4 \%)$ ), and the percentage of subjects not classified as under-reporters in any of the four methods was $34.5 \%$ ( $n$ 876; 442 men and 434 women). The analysis of the prevalence of under-reporters showed significant differences between men and women, with percentages of under-reporters being greater in women (by an average of $6 \%$ points) except

Table 2. Population with intakes below ANR cut point in the entire sample and excluding under-reporters ${ }^{\star}$

\begin{tabular}{|c|c|c|c|c|c|c|c|c|c|c|c|c|}
\hline & \multicolumn{3}{|c|}{ One 24HR (\%) } & \multicolumn{3}{|c|}{ Two 24HR (\%) } & \multicolumn{3}{|c|}{$\begin{array}{l}\text { 24HR adjusted for intraindivi- } \\
\text { dual variability (\%) }\end{array}$} & \multicolumn{3}{|c|}{ FFQ (\%) } \\
\hline & All & $\begin{array}{l}\text { Excluding } \\
\text { under- } \\
\text { reporters }\end{array}$ & Difference & All & $\begin{array}{l}\text { Excluding } \\
\text { under- } \\
\text { reporters }\end{array}$ & Difference & All & $\begin{array}{l}\text { Excluding } \\
\text { under- } \\
\text { reporters }\end{array}$ & Difference & All & $\begin{array}{l}\text { Excluding } \\
\text { under- } \\
\text { reporters }\end{array}$ & Difference \\
\hline Vitamin A & $52 \cdot 1$ & 41.7 & $10 \cdot 4$ & $47 \cdot 9$ & 38.9 & $9 \cdot 0$ & $57 \cdot 7$ & $52 \cdot 7$ & $5 \cdot 0$ & $15 \cdot 6$ & $9 \cdot 9$ & $5 \cdot 7$ \\
\hline Vitamin C & $39 \cdot 1$ & $32 \cdot 8$ & $6 \cdot 3$ & 33.0 & $29 \cdot 7$ & $3 \cdot 3$ & 22.9 & $21 \cdot 3$ & 1.6 & $9 \cdot 4$ & $7 \cdot 3$ & $2 \cdot 1$ \\
\hline Vitamin E & $78 \cdot 8$ & $66 \cdot 2$ & $12 \cdot 6$ & $80 \cdot 6$ & $70 \cdot 3$ & $10 \cdot 3$ & $96 \cdot 7$ & $94 \cdot 2$ & 2.5 & $50 \cdot 8$ & $40 \cdot 2$ & $10 \cdot 6$ \\
\hline Thiamin & 35.4 & $14 \cdot 1$ & $21 \cdot 3$ & $30 \cdot 7$ & $13 \cdot 1$ & $17 \cdot 6$ & $16 \cdot 3$ & 4.8 & 11.5 & $19 \cdot 2$ & 8.4 & $10 \cdot 8$ \\
\hline Riboflavin & $16 \cdot 0$ & 4.6 & 11.4 & $12 \cdot 5$ & $4 \cdot 0$ & 8.5 & $2 \cdot 8$ & 0.6 & $2 \cdot 2$ & $5 \cdot 8$ & $1 \cdot 3$ & 4.5 \\
\hline Niacin & $15 \cdot 7$ & $6 \cdot 0$ & $9 \cdot 7$ & $9 \cdot 8$ & $2 \cdot 9$ & $6 \cdot 9$ & 0.4 & $0 \cdot 1$ & $0 \cdot 3$ & $4 \cdot 1$ & 0.9 & 3.2 \\
\hline Vitamin $B_{6}$ & $20 \cdot 4$ & 6.5 & 13.9 & $16 \cdot 7$ & $5 \cdot 8$ & $10 \cdot 9$ & $4 \cdot 1$ & 0.7 & 3.4 & 6.7 & 1.6 & $5 \cdot 1$ \\
\hline Folate & $82 \cdot 9$ & $76 \cdot 7$ & $6 \cdot 2$ & $86 \cdot 3$ & $81 \cdot 5$ & $4 \cdot 8$ & 98.5 & $97 \cdot 6$ & 0.9 & $66 \cdot 2$ & $59 \cdot 6$ & $6 \cdot 6$ \\
\hline Vitamin $B_{12}$ & $13 \cdot 9$ & $5 \cdot 3$ & $8 \cdot 6$ & $6 \cdot 7$ & $2 \cdot 7$ & $4 \cdot 0$ & 0.2 & 0.0 & 0.2 & 0.9 & 0.1 & 0.8 \\
\hline Fe† & 29.9 & $22 \cdot 1$ & $7 \cdot 8$ & $28 \cdot 1$ & $20 \cdot 8$ & $7 \cdot 3$ & $29 \cdot 1$ & $29 \cdot 0$ & 0.1 & $20 \cdot 0$ & $15 \cdot 9$ & $4 \cdot 1$ \\
\hline $\mathrm{Mg}$ & $59 \cdot 3$ & 37.5 & $21 \cdot 8$ & $61 \cdot 0$ & 43.4 & $17 \cdot 6$ & $71 \cdot 1$ & $58 \cdot 9$ & $12 \cdot 2$ & $37 \cdot 8$ & $24 \cdot 9$ & $12 \cdot 9$ \\
\hline $\mathrm{P}$ & $5 \cdot 6$ & $1 \cdot 3$ & $4 \cdot 3$ & 3.9 & $1 \cdot 1$ & $2 \cdot 8$ & 0.7 & 0.4 & 0.3 & $1 \cdot 3$ & 0.5 & 0.8 \\
\hline $\mathrm{Zn}$ & $43 \cdot 1$ & 23.5 & $19 \cdot 6$ & $41 \cdot 7$ & 23.0 & $18 \cdot 7$ & $42 \cdot 0$ & $25 \cdot 7$ & $16 \cdot 3$ & $31 \cdot 2$ & $15 \cdot 1$ & $16 \cdot 1$ \\
\hline
\end{tabular}

ANR, average nutrient requirement; $24 \mathrm{HR}, 24 \mathrm{~h}$ recall.

*Pooled analysis of Spanish data. Population aged $12-80$ years $(n 2615)$.

$\dagger F e$ : calculated by the probability approach. 

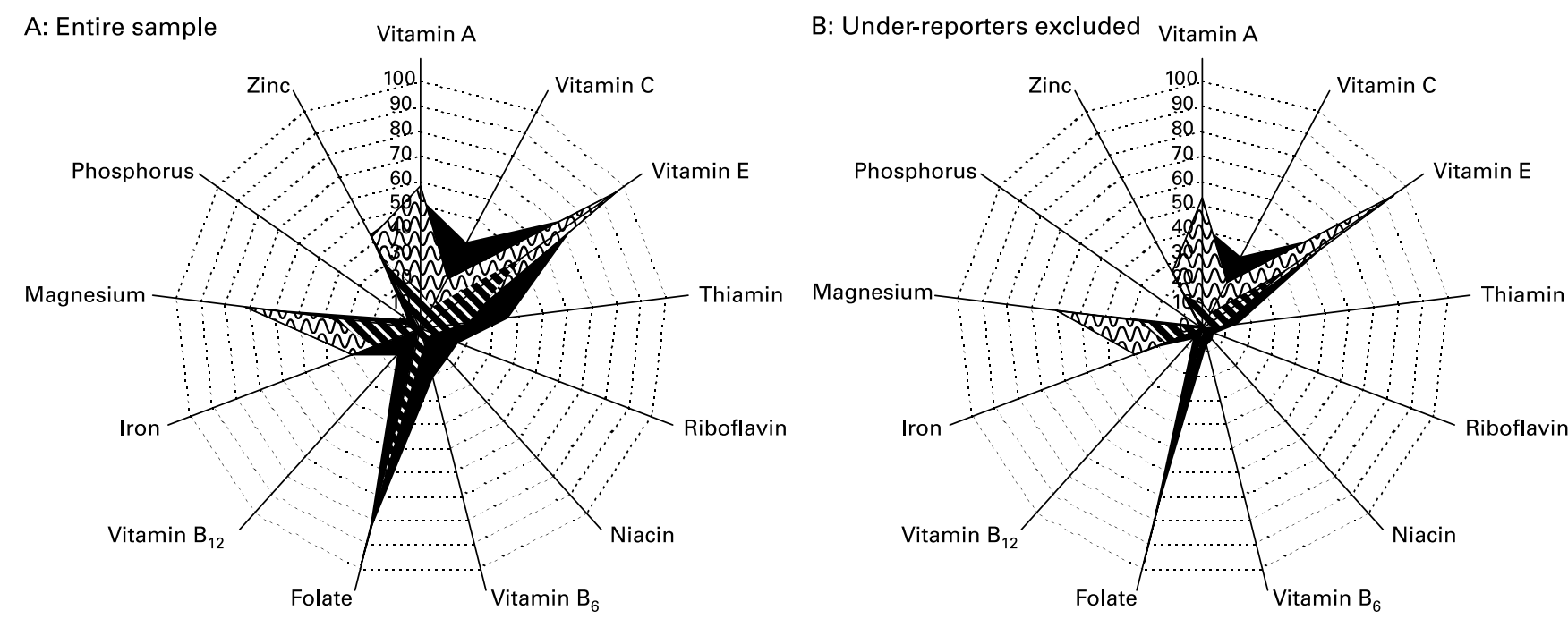

Fig. 1. Population with intakes below average nutrient requirement (\%). Pooled analysis of Spanish data (12-80 years). (A) Entire sample and (B) under-reporters excluded ( $\square, 1-24 \mathrm{~h}$ recall $(24 \mathrm{HR}) ;$

for when the FFQ was used, in which $25.7 \%$ under-reporters were women and $30.5 \%$ were men. Exclusion of under-reporters entailed a decrease in the inadequate intake percentages which, depending on the nutrient and the instrument used, ranged from 0.2 points (adjusted data for vitamin $\mathrm{B}_{12}$ ) to 21.8 points in the case of $\mathrm{Mg}(24 \mathrm{HR})$. Adjusted-data values were the least modified, followed by FFQ values (Table 2 and Fig. 1). The greatest decreases (by more than $10 \%$ points) with all methods were observed for thiamin, $\mathrm{Mg}$ and $\mathrm{Zn}$; this was also true for vitamin $\mathrm{E}$, with the exception of adjusted data.

Table 3 presents the agreement when the different methods were compared using each one as the standard to classify intakes of the various nutrients that were below the ANR cut-off point. Each of the nutrients considered (vitamin $\mathrm{C}$, folate, vitamin $B_{12}$ and $\mathrm{Zn}$ ) was analysed to see the concordance in intake inadequacy classification according to the ANR cut-off point between the different methods of data analysis used. Sensitivity, specificity and the $\kappa$ value were calculated. For vitamin $C$, the best agreement occurred when comparing repeated $24 \mathrm{HR}$ with adjusted data and in the comparison of the single 24HR with the two 24HR (good agreement). For folate, the agreement between the single $24 \mathrm{HR}$ and the repeated $24 \mathrm{HR}$ was good, and slight concordance was observed between the FFQ and the single 24HR or the mean of the two $24 \mathrm{HR}$. For vitamin $\mathrm{B}_{12}$, the agreement between the single $24 \mathrm{HR}$ and the mean of the two $24 \mathrm{HR}$ was fair. $\mathrm{Zn}$ showed the best agreement: good classification between the single $24 \mathrm{HR}$ and the mean of the two $24 \mathrm{HR}$ or the adjusted data, and slight between the FFQ with the three other methods.

\section{Discussion}

The present article compares the prevalence of inadequate intakes for certain micronutrients in a pool of two population-based studies defining inadequacy as intakes below the ANR cut-point for all study nutrients except $\mathrm{Fe}$, for which the probability approach was applied. A daily method
(24HR) and a FFQ were the dietary instruments applied to each individual that provided data allowing for analyses based on a single $24 \mathrm{HR}$, two $24 \mathrm{HR}$ over non-consecutive days, adjusted 24HR and the FFQ. There is no single ideal method to estimate intake for the evaluation of nutritional adequacy in individuals and populations. The most adequate method will depend on the situation, the study objectives and nutrients to be considered, among others. No method is perfect, and each one of them presents both advantages and disadvantages $(1,2,13,28)$.

In order to assess the prevalence of inadequate intakes in a population, it is essential to know the usual intake of the individuals comprising the given population ${ }^{(26)}$. Usual intake can be measured by administering a quantitative or semi-quantitative FFQ or by daily methods if they are administered on repeated occasions and/or utilise statistical modelling techniques to adjust for intra-individual variability in data derived from two or more records/24HR (obtained from the entire study sample or from a subsample).

When planning a dietary survey, apart from choosing the dietary instrument to utilise, the number of days of administration should also be considered. The intake of each individual varies from day to day ${ }^{(29,30)}$. Variability in dietary intake influences the number of days required to estimate food and nutrients accurately ${ }^{(31-33)}$. In general, the number of days needed for recording intake of nutrients habitually present in the diet of some subjects but not others (i.e. sugar) is less. Contrariwise, for nutrients that are consumed in large quantities but only occasionally by almost all study subjects (i.e. carotene, $\mathrm{Cu}$, etc.), more recording days are required. Furthermore, this will also depend on the characteristics of the study population. Obtaining the true average intake at the individual level requires a much higher number of recalls/records that can vary from one individual to another (i.e. from 30 to 168 for $\mathrm{Ca}$ ) or from one nutrient to another (from 14 to 84 for energy and from 115 to more than 1000 for vitamin A). In groups of individuals, obtaining the true average intake can be achieved either by increasing the number of food records (i.e. $3 \mathrm{~d}$ for estimating energy, $42 \mathrm{~d}$ for vitamin $\mathrm{A}$ 
Table 3. Agreement between different methods in the classification of intakes below the ANR for vitamin C, folate, vitamin $B_{12}$ and $Z n^{*}$

Reference method used as standard

\begin{tabular}{|c|c|c|c|c|c|c|c|c|c|c|c|c|}
\hline & \multicolumn{3}{|c|}{ One $24 \mathrm{HR}$} & \multicolumn{3}{|c|}{ Two 24HR } & \multicolumn{3}{|c|}{ Adj. $24 \mathrm{HR}$} & \multicolumn{3}{|c|}{$\mathrm{FFQ}$} \\
\hline & SE & SP & $\kappa$ & SE & SP & $\kappa$ & SE & SP & $\kappa$ & SE & SP & $\kappa$ \\
\hline \multicolumn{13}{|l|}{ Vitamin C } \\
\hline One $24 \mathrm{HR}$ & & & & 83.8 & 82.9 & $0.637 \dagger$ & 95.5 & $77 \cdot 6$ & $0.585 \ddagger$ & $70 \cdot 5$ & $64 \cdot 2$ & $0 \cdot 144 \|$ \\
\hline Two $24 \mathrm{HR}$ & $70 \cdot 8$ & $91 \cdot 2$ & $0.637 \dagger$ & & & & $90 \cdot 8$ & $84 \cdot 1$ & $0.648 \dagger$ & $69 \cdot 2$ & $70 \cdot 7$ & $0 \cdot 189 \|$ \\
\hline Adj. 24HR & $55 \cdot 8$ & $98 \cdot 3$ & $0.585 \ddagger$ & $62 \cdot 9$ & $96 \cdot 9$ & $0.648 \dagger$ & & & & 55.5 & 80.5 & $0.220 \S$ \\
\hline FFQ & $17 \cdot 0$ & $95 \cdot 4$ & $0 \cdot 144 \|$ & $19 \cdot 8$ & $95 \cdot 7$ & $0.189 \|$ & 22.9 & $94 \cdot 6$ & $0.220 \S$ & & & \\
\hline \multicolumn{13}{|l|}{ Folate } \\
\hline One $24 \mathrm{HR}$ & & & & $92 \cdot 7$ & $79 \cdot 0$ & $0.648 \dagger$ & $84 \cdot 2$ & $100 \cdot 0$ & $0 \cdot 140 \|$ & $89 \cdot 1$ & $20 \cdot 3$ & $0.210 \S$ \\
\hline Two $24 \mathrm{HR}$ & 96.5 & $63 \cdot 1$ & $0.648 \dagger$ & & & & 87.7 & 97.5 & $0 \cdot 174 \|$ & $92 \cdot 6$ & $25 \cdot 8$ & $0.215 \S$ \\
\hline Adj. 24HR & $100 \cdot 0$ & $9 \cdot 0$ & $0 \cdot 140 \|$ & $100 \cdot 0$ & $10 \cdot 9$ & 0.1749 & & & & 99.5 & 3.6 & $0.041 \|$ \\
\hline FFQ & $71 \cdot 2$ & $57 \cdot 9$ & $0.210 \S$ & $71 \cdot 0$ & 63.9 & $0.215 \S$ & 66.9 & $80 \cdot 0$ & $0.041 \|$ & & & \\
\hline \multicolumn{13}{|l|}{ Vitamin $B_{12}$} \\
\hline One $24 \mathrm{HR}$ & & & & $76 \cdot 6$ & $90 \cdot 6$ & $0.447 \ddagger$ & $100 \cdot 0$ & $86 \cdot 2$ & $0 \cdot 019 \|$ & $66 \cdot 7$ & $86 \cdot 6$ & $0.066 \|$ \\
\hline Two $24 \mathrm{HR}$ & $36 \cdot 8$ & 98.2 & $0.447 \ddagger$ & & & & $50 \cdot 0$ & 93.4 & $0.019 \|$ & $54 \cdot 2$ & 93.8 & 0.116 \\
\hline Adj. 24HR & $1 \cdot 1$ & $100 \cdot 0$ & $0.019 \|$ & $1 \cdot 1$ & 99.9 & $0.019 \|$ & & & & 0.0 & 99.9 & -0.0039 \\
\hline FFQ & 4.4 & 99.6 & $0.066 \|$ & $7 \cdot 4$ & $99 \cdot 6$ & $0 \cdot 116 \|$ & 0.0 & $99 \cdot 1$ & -0.0039 & & & \\
\hline \multicolumn{13}{|l|}{$\mathrm{Zn}$} \\
\hline One 24HR & & & & $82 \cdot 3$ & 84.9 & $0.668 \dagger$ & 84.6 & 86.9 & $0.712 \dagger$ & $63 \cdot 2$ & $66 \cdot 0$ & $0.264 \S$ \\
\hline Two 24HR & 79.5 & $87 \cdot 0$ & $0.668 \dagger$ & & & & $76 \cdot 0$ & $83 \cdot 2$ & $0.593 \ddagger$ & $61 \cdot 7$ & $67 \cdot 4$ & $0.267 \S$ \\
\hline Adj. 24HR & $82 \cdot 3$ & $88 \cdot 6$ & $0.712 \dagger$ & $76 \cdot 6$ & $82 \cdot 8$ & $0.593 \ddagger$ & & & & $67 \cdot 1$ & $69 \cdot 4$ & $0.334 \S$ \\
\hline FFQ & $45 \cdot 8$ & $79 \cdot 8$ & $0.264 \S$ & $46 \cdot 3$ & 79.5 & $0.267 \S$ & 49.9 & $82 \cdot 3$ & $0.334 \S$ & & & \\
\hline
\end{tabular}

ANR, average nutrient requirement (or estimated average requirement); $24 \mathrm{HR}, 24 \mathrm{~h}$ recall; Adj., adjusted; SE, sensibility; SP, specificity.

* Pooled analysis of Spanish data. Population aged $12-80$ years.

† Good, $0 \cdot 6-0.8$

$\ddagger$ Fair, 0.4-0.6.

§Slight, $0.2-0.4$

|l Poor, 0-0.2.

I No agreement, $-1-0$.

assessment) or by increasing the number of study subjects. At both the individual or group level, food energy required the fewest daily records and vitamin A the most $\mathrm{t}^{(29,31,34)}$. Ideally, all the days of the week should be represented as well as all the seasons in a year. In practice, acquiring these types of data is almost impossible as it requires a high level of motivation from study participants, while simultaneously requiring that study participation does not influence their eating habits.

Be that as it may, the $24 \mathrm{HR}$ is one of the most commonly accepted and applied instruments used in population-based nutrition studies ${ }^{(35-37)}$. In 2002, the European Project European food consumption survey method (EFCOSUM), whose objective was to develop a method for a European food consumption survey that derives internationally comparable data on a set of policy-relevant nutritional indicators, published recommendations on methodologies that should be applied to forthcoming new nutrition studies. The method of choice deemed as the most suitable for obtaining population means and distributions was a $24 \mathrm{HR}$ repeated at least once over non-consecutive days, so as to be able to estimate usual intake within a given population ${ }^{(38)}$. Moreover, the EFCOSUM project conducted a thorough analysis of distinct statistical methods applied to estimate habitual intake in a population based on two or more $24 \mathrm{HR}$, paying special attention that all days of the week and seasonal variation were taken into account ${ }^{(39)}$. Out of the six methods analysed (Slob 1993, Wallace 1994, Buck 1995, Nusser 1996, Gay 2000 and a simplified Nusser method) ${ }^{(39-45)}$, it was recommended to use the method developed by Nusser and the simplified version $^{(39,43,44)}$. Still and all, the complexity of applying
Nusser's method and the necessity of having specific software (side and $\mathrm{C}$-side) and their required operating systems to conduct analysis have led to infrequent application of this procedure $^{(39)}$.

Characteristics of the estimated usual intake distribution include a decreased standard deviation, increased lower percentiles and decreased upper percentiles when compared with the actual intake distribution of individual means ${ }^{(39)}$. It is obvious that the information provided by a single $24 \mathrm{HR}$ can not be used to assess the risk of inadequate intakes; even the use of two $24 \mathrm{HR}$ or records will not provide an exact estimate of the individual's usual intake and lead to distributions with too large a variance, and, consequently, the prevalence of nutrient inadequacy in a group may be significantly biased $^{(46)}$. However, although we are aware that more dietary recalls/records are needed from each person, when no other information is available, their application has become common practice. As such, the present analysis has included data on actual intake.

The ANR cut-off point was chosen for assessing inadequate intakes as it had been validated using the probability approach and the Monte Carlo simulation ${ }^{(47)}$, as well as having confirmed its extreme usefulness and ease of application. If the conditions for its use are met, the ANR cut-off point can provide a valid estimation of the prevalence of inadequate intake at the population level when the requirement is symmetrically distributed about the estimated average requirement. The present study data have been analysed using different cut-off points of the individual nutrient level at $98 \%$ (INL 98 , also known as the RDA), which are usually used in population 
studies to assess the risk of inadequate intakes, such as intakes $<1 / 3$ INL $_{98},<1 / 2$ INL $_{98},<2 / 3$ INL $_{98}$, etc. (data not shown). However, it was decided to only present data corresponding to the ANR cut-off point as it is presently the recommended method to estimate inadequate intakes at the population level. Moreover, the ANR of a nutrient shows the average requirement of the population (assuming a symmetrical distribution) and it does not represent a fixed percentage of the INL $_{98}{ }^{(48)}$. How the ANR corresponds with the percentage of $\mathrm{INL}_{98}$ depends on the $\mathrm{CV}$ and this is a variable depending on the nutrient and the population ${ }^{(49)}$. In this way, a $\mathrm{CV}$ of $10 \%$ represents $83 \%$ of the $\mathrm{INL}_{98}$, a CV of $15 \%$ represents $77 \%$ of the $\mathrm{INL}_{98}$ and a CV of $20 \%$ represents $71 \%$ of the INL $_{98}$. Such percentages of INL $_{98}$ are greater than those analysed with the cut-off points $<1 / 3$ INL $_{98}(33 \%),<1 / 2$ INL $_{98}$ $(50 \%)$ and $<2 / 3$ INL $_{98}(66 \%)$.

Although the study population was Spanish, the Spanish recommendations were not chosen as they did not include ANR values; as such, we opted to use the recently published American recommendations and those of $\mathrm{WHO}^{(24,25)}$. Generally, another problem linked to reference values was that sometimes it was not known whether the value shown in the table referred to the ANR or the INL 98 . Furthermore, the $\mathrm{CV}$ for each nutrient was not always available to allow for calculating the ANR from the INL 98 . In fact, the objective of the present article was not to obtain the prevalence of inadequate intakes of a population, but to compare the values obtained with the different dietary analysis methods that are presently being used in nutrition studies. Whether we choose the American, WHO, the Nordic or any other source of reference values is irrelevant to the present analysis as the objective was not to obtain the absolute prevalence values of inadequate intakes. The prevalence of inadequacy may increase or decrease depending on the reference values applied, but the influence will be of the same degree over the four dietary methods analysed.

The recommendations from the EFCOSUM project reaffirm the utility of the $24 \mathrm{HR}$ as the method of choice in studies monitoring the nutritional status of populations, with the administration of two recalls in the entire sample and adjustment for intra-individual variability according to the method developed by Nusser ${ }^{(35,39)}$. The two studies that comprise this 'pooled' analysis are part of the nutrition-monitoring system in the regions they represent, which were conducted before the publication of the EFCOSUM recommendations. Still and all, the methodology utilised was quite similar to the EFCOSUM recommendations, applying two 24HR over non-consecutive days (in the entire sample in the Canary Islands Nutrition Survey and in a subsample in the Catalan Nutrition Survey) that represented all days of the week and seasonal variations. Additionally, crude data for energy and nutrients were also adjusted for intra-individual variability following the method described by Liu et al. ${ }^{(12)}$ and Beaton et al. ${ }^{(13)}$. It is not clear the need to collect a second recall or record in all of the sample or in just a subsample. With the objective of evaluating consumption habits, both studies administered a FFQ. The aim of the FFQ was to assess the frequency with which certain food items or food groups were consumed during a specified time period. The estimation of a standard portion or portions actually consumed allowed for the quantification of usual intake as well as for the calculation of energy and nutrient intakes ${ }^{(1,2)}$. The FFQ has been shown to be of great utility in studies that relate intake to disease outcomes. The development of the food list is crucial to successful and reliable data collection ${ }^{(1,2,7,35)}$.

The analysis of agreement between the different methods shows greater concordance among daily methods and less agreement when compared with the FFQ. This finding is not a surprise, given the intrinsic relationship existing among the three daily methods. Once again, differences were observed depending on the nutrient being analysed. The comparison of the two methods that utilised usual intake (FFQ and 24HR adjusted data) showed low levels of agreement.

The data analysed showed a diverse range of inadequate intake percentages, depending on the method utilised (if usual or actual intake was analysed) and the nutrient under study. The effect of utilising two non-consecutive $24 \mathrm{HR}$ when compared with a single $24 \mathrm{HR}$ showed a slight decrease in the prevalence of inadequate intakes for the majority of nutrients (which reached $7 \%$ points in the case of vitamin $\mathrm{B}_{12}$ ). The methods that measured usual intakes had values that were markedly lower than those obtained by daily methods, with the exception of adjusted data for vitamin $\mathrm{A}$, vitamin $\mathrm{E}$, folate and $\mathrm{Mg}$, which increased. $\mathrm{Zn}$ is the nutrient that presented similar values across all methods analysed. In general, the prevalence of inadequate intake decreased in conjunction with the method utilised in the following order: single 24HR, mean of two $24 \mathrm{HR}$, FFQ and 24HR-adjusted data, the latter showing exceptions for the four previously mentioned nutrients, which showed lower prevalences of inadequacies with the FFQ.

When analysing inadequate intake prevalence in nutrition studies, the problem of misreporting emerges. Under-reporting of energy generally leads to the under-reporting of nutrients ${ }^{(3,50)}$. The degree to which it affects each nutrient remains to be clarified, although the analysis of certain nutrients has shown that under-reporting of energy accounts for approximately $30 \%$ of under-reporting of $\mathrm{Fe}, \mathrm{Ca}$ or vitamin $\mathrm{C}^{(50)}$. The present study presents a high number of under-reporters that may be due to diverse causes (voluntary omission of foods consumed, erroneous estimation of portion sizes eaten, memory lapses, etc.), which is well described in the review article by Poslusna et al. ${ }^{(50)}$. One way of reducing and improving the quality of $24 \mathrm{HR}$ to diminish misreporting could be the realisation of computer-assisted interviews. In the previously cited review, one of the recommendations to deal with the issue of under-reporting in nutrition studies is to compare intakes of the group with and without misreporters and then use the difference as a part of uncertainty evaluation $^{(50)}$. As the present results demonstrate, the exclusion of under-reporters led to a decrease in inadequacy prevalence, which varied depending on the method and nutrient under study and which showed marked reductions for thiamin, $\mathrm{Mg}$ and $\mathrm{Zn}$.

An important aspect to consider for the correct assessment of inadequate vitamin and mineral intakes is the evaluation of multivitamin supplement consumption and the variability of this intake. Nutrition studies frequently obtain information on supplement use, but its correct assessment is often not possible. To achieve this, it is necessary to know supplement consumption patterns, the numbers of non-consumers, those with sporadic consumption in times of illness and those who 
take supplements on a regular basis. Nutrient intake can be summed from data derived from the diet and supplement use and then adjusted for intra-individual variability, or dietary intake data may first be adjusted and then supplement data added $^{(46)}$. In the present study, supplement data obtained from questionnaires did not permit the quantification of daily intake and as such, supplements were not considered in the analysis.

The present study's analysis has compared the prevalence of inadequate intakes for the entire sample as well as excluding under-reporters. Important differences were observed according to the method applied and nutrient under study, with higher prevalences seen for a single 24HR and lower values with data adjusted for intra-individual variability. Reproducibility of daily methods was also reasonably good. Results differed depending on the micronutrient analysed, thus impeding reaching conclusions/recommendations common to all micronutrients.

\section{Acknowledgements}

The study reported herein have been carried out within the EURRECA Network of Excellence (www.eurreca.org), financially supported by the Commission of the European Communities, specific Research, Technology and Development Programme Quality of Life and Management of Living Resources, within the Sixth Framework Programme, Contract no. 036196. The present report does not necessarily reflect the Commission's views or its future policy in this area. L. R.-B undertook analysis, screened the literature and wrote the paper. L. S.-M. was supervisor of the study, participated in its design and revised the paper providing expert advice on data interpretation and discussion of the paper. B. R. V. contributed to the literature search, screened part of the literature and commented on drafts of the paper. J. N. and A. G.-A. commented on drafts of the paper. The authors have no conflict of interests to report.

\section{References}

1. Serra Majem L \& Aranceta Bartrina J (editors) (2006) MassonNutrición y Salud Pública. Métodos, bases científicas y aplicaciones. (Public Health Nutrition. Methods, and Scientific Applications), 2nd ed. Barcelona.

2. Gibson RS (2005) Principles of Nutritional Assessment, 2nd ed. New York: Oxford University Press.

3. Becker W \& Welten D (2001) Under-reporting in dietary surveys - implications for development of food-based dietary guidelines. Public Health Nutr 4, 683-687.

4. Winichagoon P (2008) Limitations and resolutions for dietary assessment of micronutrient intakes. Asia Pac J Clin Nutr 17, Suppl. 1, 296-298.

5. Pérez Rodrigo C (2006) Fuentes de error en la evaluación del consumo de alimentos. (Sources of error in the assessment of food consumption). In Nutrición y Salud Pública. Métodos, bases cientificas y aplicaciones. (Public Health Nutrition. Methods, and Scientific Applications), 2nd ed., pp. 245-253. Barcelona: Masson.

6. Beaton GH (1994) Approaches to analysis of dietary data: relationship between planned analyses and choice of methodology. Am J Clin Nutr 59, 1 Suppl, 253S-261S.
7. Willett W (1998) Nutritional Epidemiology, 2nd ed. New York: Oxford University Press.

8. Beaton GH, Milner J, Corey P, et al. (1979) Sources of variance in 24 hour dietary recall data; implications for nutrition study design and interpretation. Am J Clin Nutr 32, 2546-2559.

9. Hartman AM, Brown CC, Palmgren J, et al. (1990) Variability in nutrient and food intakes among older middle-aged men. Implications for design of epidemiologic and validation studies using food recording. Am J Epidemiol 132, 999-1012.

10. Tokudome Y, Imaeda N, Nagaya T, et al. (2002) Daily, weekly, seasonal, within- and between-individual variation in nutrient intake according to four season consecutive 7 day weighed diet records in Japanese female dietitians. J Epidemiol 12, 85-92.

11. Lanigan JA, Wells JC, Lawson MS, et al. (2004) Number of days needed to assess energy and nutrient intake in infants and young children between 6 months and 2 years of age. Eur J Clin Nutr 58, 745-750.

12. Liu K, Stamler J, Dyer A, et al. (1978) Statistical methods to assess and minimize the role of intraindividual variability in obscuring the relationship between dietary lipids and serum cholesterol. J Chronic Dis 31, 399-418.

13. Beaton GH, Milner J, McGuire V, et al. (1983) Sources of variance in 24 hour dietary recall data: implications for nutrition study design and interpretation. Carbohydrate sources, vitamins and minerals. Am J Clin Nutr 37, 986-995.

14. Dodd KW, Guenther PM, Freedman LS, et al. (2006) Statistical methods for estimating usual intake of nutrients and foods: a review of the theory. J Am Diet Assoc 106, 1640-1650.

15. Ashwell M, Lambert JP, Alles MS, et al. (2008) How we will produce the evidence-based EURRECA toolkit to support nutrition and food policy. Eur J Nutr 47, Suppl. 1, 2-16.

16. King JC, Vorster HH \& Tome DG (2007) Nutrient intake values (NIVs): a recommended terminology and framework for the derivation of values. Food Nutr Bull 28, Suppl. International, S16-S26.

17. Serra Majem L, Ribas Barba L, Salvador Castell G, et al. (2006) Avaluació de l'estat nutricional de la població catalana 20022003. Evolució dels hàbits alimentaris $i$ dels consum d'aliments i nutrients a Catalunya (1992-2003). (Assessment of the Nutritional Status of the Catalan Population 2002-2003. Trends in Dietary Habits and Consumption of Food and Nutrients in Catalonia, 1992-2003). Barcelona: Departament de Salut, Generalitat de Catalunya.

18. Serra-Majem L \& Ribas Barba L (editors) (2007) Trends in nutrition status in Catalonia, Spain (1992-2003). Public Health Nutr 10, 1339-1414.

19. Serra-Majem L (editor) (2000) Evaluación del estado nutricional de la población Canaria (1997-98). (Assessment of nutritional status of the Canary Islands population (1997-98)). Arch Latinoamer Nutr 50, Suppl. 1, 1-70.

20. Serra Majem L (1999) Encuesta de Nutrición de Canarias 1997-1998. (Nutrition Survey of the Canary Islands 19971998). Las Palmas de Gran Canaria: Servicio Canario de Salud. Consejería de Sanidad y Asuntos Sociales. Gobierno de Canarias. http://www.gobiernodecanarias.org/sanidad/scs/1/ plansalud/enca/ppal_enca.htm

21. CESNID (2002) Tablas de composición de alimentos. (Food Composition Tables). Barcelona: Edicions Universitat de Barcelona-Centre d'Ensenyament Superior de Nutrició i Dietètica.

22. Mataix J, Mañas M, Llopis J, et al. (1998) Tabla de composición de alimentos españoles. (Spanish Food Composition Table), 3rd ed. Granada: Universidad de Granada.

23. Goldberg GR, Black AE, Jebb SA, et al. (1991) Critical evaluation of energy intake data using fundamental principles of energy physiology. 1. Derivation of cut-off limits to identify under-recording. Eur J Clin Nutr 45, 469-481. 
24. Institute of Medicine of the National Academies (2006) Dietary Reference Intakes. The Essential Guide to Nutrient Requirement. [JJ Otten, JP Hellwig and LD Meyers, editors]. Washington, DC: The National Academy Press.

25. World Health Organization, Food and Agriculture Organization of the United Nations (2004) Vitamin and Mineral Requirements in Human Nutrition, 2nd ed. Geneva: World Health Organization and Rome/Food and Agriculture Organization of the United Nations, available at http://whqlibdoc.who.int/ publications/2004/9241546123.pdf (accessed 28 January 2009).

26. Carriquiry AL (1999) Assessing the prevalence of nutrient inadequacy. Public Health Nutr 2, 23-33.

27. Murphy SP, Guenther PM \& Kretsch MJ (2006) Using the dietary reference intakes to assess intakes of groups: pitfalls to avoid. J Am Diet Assoc 106, 1550-1553.

28. Thompson FE \& Subar AF (2008) Dietary assessment methodology. In Nutrition in the Prevention and Treatment of Disease, 2nd ed., pp. 3-37 [AM Coulston and CJ Boushey, editors]. Washington, DC: Academic Press.

29. Nelson M, Black AE, Morris JA, et al. (1989) Between- and within-subject variation in nutrient intake from infancy to old age: estimating the number of days required to rank dietary intakes with desired precision. Am J Clin Nutr 50, 155-167.

30. Sempos CT, Johnson NE, Smith EL, et al. (1985) Effects of intraindividual and interindividual variation in repeated dietary recalls. Am J Epidemiol 121, 20-130.

31. Palaniappan U, Cue RI, Payette H, et al. (2003) Implications of day-to-day variability on measurements of usual food and nutrient intakes. J Nutr 133, 232-235.

32. Tarasuk V \& Beaton GH (1992) Statistical estimation of dietary parameters: implications of patterns in within-subject variation - a case study of sampling strategies. Am J Clin Nutr 55, 22-27.

33. Volatier JL, Turrini A \& Welten D (2002) Some statistical aspects of food intake assessment. Eur J Clin Nutr 56, Suppl. 2, S46-S52.

34. Basiotis PP, Welsh SO \& Cronin FJ (1987) Number of days of food intake records required to estimate individual and group nutrient intakes with defined confidence. $J$ Nutr 117, $1638-1641$.

35. Biro G, Hulshof KFAM, Ovesen L, et al. (2002) Selection of methodology to assess food intake. Eur J Clin Nutr 56, S25-S32.

36. Verger P, Ireland J, Møller A, et al. (2002) Improvement of comparability of dietary intake assessment using currently available individual food consumption surveys. Eur $\mathrm{J}$ Clin Nutr 56, Suppl. 2, S18-S24

37. Elmadfa I, Weichselbaum E, Konig J, et al. (2005) European nutrition and health report 2004. Forum Nutr 58, 1-220.

38. Brussaard JH, Löwik MR, Steingrímsdóttir L, et al. (2002) A European food consumption survey method - conclusions and recommendations. Eur J Clin Nutr 56, Suppl. 2, S89-S94.

39. Hoffmann K, Boeing H, Dufour A, et al. (2002) Estimating the distribution of usual dietary intake by short-term measurements. Eur J Clin Nutr 56, Suppl. 2, S53-S62.

40. Slob W (1993) Modeling long-term exposure of the whole population to chemicals in food. Risk Anal 13, 25-30.

41. Wallace LA, Duan N \& Ziegenfus R (1994) Can long-term exposure distributions be predicted from short-term measurements? Risk Anal 14, 75-85.

42. Buck RJ, Hammerstrom KA \& Ryan PB (1995) Estimating long-term exposures from short-term measurements. $J$ Expo Anal Environ Epidemiol 5, 359-373.

43. Nusser SM, Carriquiry AL, Dodd KW, et al. (1996) A semiparametric transformation approach to estimating usual daily intake distributions. J Am Statist Assoc 91, 1440-1449.

44. Guenther PM, Kott PS \& Carriquiry AL (1997) Development of an approach for estimating usual nutrient intake distributions at the population level. $J$ Nutr 127, 1106-1112.

45. Gay C (2000) Estimation of population distributions of habitual nutrient intake based on a short-run weighed food diary. $\mathrm{Br} \mathrm{J}$ Nutr 83, 287-293.

46. Carriquiry AL (2003) Estimation of usual intake distributions of nutrients and foods. $J$ Nutr 133, 601S-608S.

47. de Lauzon B, Volatier JL \& Martin A (2004) A Monte Carlo simulation to validate the EAR cut-point method for assessing the prevalence of nutrient inadequacy at the population level. Public Health Nutr 7, 893-900.

48. Román-Viñas B, Serra-Majem L, Ribas-Barba L, et al. (2009) Overview of methods used to evaluate the adequacy of nutrient intakes for individuals and populations. Br J Nutr 101, Suppl. 2, S6-S11.

49. Beaton GH (1985) Uses and limits of the use of the recommended dietary allowances for evaluating dietary intake data. Am J Clin Nutr 41, 155-164.

50. Poslusna K, Ruprich J, de Vries JHM, et al. (2009) Misreporting of energy and micronutrient intake estimated by food records and 24 hour recalls, control and adjustment methods in practice. Br J Nutr 101, Suppl. 2, S73-S85. 